\title{
PENGENALAN SEJAK DINI PROFESI APOTEKER MELALUI METODE STORYTELLING BERMUATAN PENDIDIKAN KARAKTER
}

\author{
Rina Wijayanti' ${ }^{1)}$, Oktarina Puspita Wardani ${ }^{2)}$ \\ 1 Fakultas Kedokteran, Universitas Islam Sultan Agung \\ email:wijayanti@unissula.ac.id \\ 2 Fakultas Keguruan dan Ilmu Pendidikan, Universitas Islam Sultan Agung \\ email: oktarinapw@unissula.ac.id
}

Corresponding author:wijayanti@unissula.ac.id

\begin{abstract}
Informasi Artikel
Diterima Redaksi: 14 August 2019

Revisi Akhir: 16 Sept 2019

Diterbitkan Online: 27 Sept 2019

Kata Kunci

Early childhood, Pharmacist Profession, Medicine, Storytelling

Korespondensi

No. HP: 085664170766
\end{abstract}

\begin{abstract}
Early childhood (2-6 years) is a golden age as well as an appropriate time to start character education and learn various skills that are useful for children as a foundation for higher skills in the future. The application of character education at that age will continue to imprint and underpin good character values that are beneficial to the child's future. TK Senyiur Indah is one of the educational institutions implementing character education through the implementation of the 2013 Curriculum. One of the themes raised in character education at TK Senyiur Indah is Work or Profession. However, the introduction of the health profession that was delivered at the time of learning activities at the Beautiful Senyiur Kindergarten was only limited to the profession of doctors and nurses. Students have not been introduced to the pharmacist profession. Whereas in fact, the pharmacist profession plays an important role in the success of health programs. The purpose of this service is to increase students' knowledge about the pharmacist profession through storytelling activities containing character education as an effort to improve health. The method used in this community service activity is the early introduction of the pharmacist profession, using the storytelling method using visual aids such as finger puppets, as well as games about the process of making drugs in the form of capsules. Solution to the agreement with partners can be seen through indicators of the success of this activity as measured by increasing the acquisition of pretest and posttest scores, which shows an increase in students' knowledge. The conclusion in this activity is the high enthusiasm of students so as to increase knowledge, skills, students in terms of medicine and the pharmacist profession so as to improve students' health.
\end{abstract}

\section{PENDAHULUAN}

Program penggiatan pendidikan berkarakter dimulai sejak anak usia dini. Hal ini didukung dengan program Pemerintah yang semakin memperluas akses PAUD, terbukti jumlah PAUD hingga akhir tahun 2013, dari total 77.559 desa se Indonesia, tercatat sebanyak 53.832 desa sudah terlayani PAUD [1]. Tak dapat dipungkiri bahwa anak usia dini (2-6 tahun) merupakan masa keemasan (golden age) sekaligus menjadi waktu yang tepat untuk mengawali pendidikan karakter dan belajar berbagai skill yang berguna bagi anak sebagai landasan skill yang lebih tinggi di masa yang akan datang. Penerapan pendidikan karakter pada usia tersebut akan terus membekas dan mendasari nilai karakter yang baik yang bermanfaat bagi masa depan anak.
Pembinaan program pendidikan kesehatan dan pelayanan kesehatan yang dilakukan selaras dengan kampanye yang telah dilakukan WHO Global School Health Initiative mulai tahun 1995 dalam usaha untuk memobilisasi dan memperkuat kegiatan promosi kesehatan baik di tingkat lokal, nasional, regional maupun global. Promosi kesehatan yang diselenggarakan oleh sekolahsekolah di Indonesia adalah implementasi kebijakan sekolah sehat yang diperkenalkan oleh WHO pada tahun $1995^{[2]}$.

Salah satu Profesi kesehatan yang mendukung promosi kesehatan adalah Apoteker. Profesi apoteker memegang peranan penting dalam menyukseskan program kesehatan. Profesi Apoteker berkontribusi dalam pelayanan obat, peracikan, hingga 
pemberian informasi penggunaan obat yang tepat sehingga tujuan terapi dapat tercapai. Komponen lain yang turut mendukung tercapainya peningkatan kesehatan adalah obat. Pada dasarnya obat memiliki dua sisi yang berbeda, yakni sisi sebagai agen penyembuh, dan sisi sebagai agen toxic. Obat dan pemanfaatannya, apabila tidak diperkenalkan sejak dini, maka dapat berpotensi memberikan dampak buruk bagi anak-anak sebagai generasi penerus bangsa.

Penanaman pemahaman mengenai profesi apoteker, obat dan pemanfaatannya perlu dilakukan sejak dini. Hal ini dilakukan guna mengantisipasi minimnya pengetahuan masyarakat mengenai profesi apoteker dan bagaimana perannya sehingga berdampak pada kurangnya informasi mengenai obat. Permasalahan ini tidak hanya terjadi pada masyarakat usia dewasa, namun juga dialami oleh anak-anak. Sikap anak-anak yang enggan minum obat pada saat sakit dikarenakan anggapan bahwa obat merupakan "hukuman" akibat kenakalannya, didukung oleh rasa pahit dan tidak enak dari obat. Keengganan minum obat oleh anak-anak ini menyebabkan turunnya kepatuhan pasien dalam mengkonsumsi obat, tentu saja berdampak pada tidak tercapainya tujuan terapi. Hasil penelitian yang dilakukan oleh Arfania, M., dkk (2015) $)^{[3]}$ menyimpulkan bahwa Drug Related Problems pasien pediatrik di instalasi rawat jalan di RS PKU Muhammadiyah Yogyakarta dan RSUD Kabupaten Sleman yang mayoritas terjadi salah satunya adalah kepatuhan $(9,88 \%)$.

Dalam hal ini, sekolah selaku pelaku transfer pendidikan memegang peranan sangat penting dalam menanamkan informasi mengenai apoteker, obat, dan pemanfaatannya. TK Senyiur Indah merupakan salah satu institusi pendidikan yang berkontribusi dalam melakukan transfer pendidikan pada anak-anak usia dini. TK Senyiur Indah yang beralamatkan di Jl. Watukaji No 45 Gedawang, Kecamatan Banyumanik, Kota Semarang, Provinsi Jawa Tengah ini memiliki jumlah siswa sebanyak 40 . Dalam kegiatan belajar mengajar, siswa siswi tersebut difasilitasi dengan 3 ruang kelas, Laboratorium Komputer sebanyak 1 ruang, Perpustakaan 1, Toilet 4, serta 1 ruang UKS yang belum termanfaatkan secara optimal.

TK Senyiur Indah menerapkan pendidikan karakter melalui pelaksanaan Kurikulum 2013 (K 13). Proses kegiatan belajar mengajar telah ditetapkan berbagai tema yang dikembangkan lebih lanjut oleh guru. Salah satu tema yang diangkat dalam pendidikan karakter di TK Senyiur Indah adalah Pekerjaan atau Profesi. Namun, pengenalan profesi kesehatan yang disampaikan pada waktu kegiatan pembelajaran di TK Senyiur Indah hanyalah sebatas pada profesi dokter dan perawat. Berdasarkan wawancara pendahuluan dengan Kepala Sekolah, dalam tema pengenalan profesi tersebut, penyerahan obat dan informasi penggunaan obat dilakukan oleh profesi dokter, yang seharusnya merupakan wewenang dan tanggungjawab profesi apoteker. Peserta didik belum diperkenalkan dengan profesi apoteker. Padahal sejatinya, profesi apoteker memegang peranan penting dalam menyukseskan program kesehatan. Profesi Apoteker berkontribusi dalam pelayanan obat, peracikan, hingga pemberian informasi penggunaan obat yang tepat sehingga tujuan terapi dapat tercapai. Apoteker bersama dengan tenaga kesehatan lainnya yaitu dokter, perawat, bidan, dan dokter gigi turut berperan dalam penanganan masalah-masalah pasien di tingkat individu maupun masyarakat ${ }^{[4]}$.

Selain itu, peserta didik juga belum diperkenalkan tentang obat dan pemanfaatannya secara tepat. Pada dasarnya obat memiliki dua sisi yang berbeda, yakni sisi sebagai agen penyembuh, dan sisi sebagai agen toxic. Apabila tidak diperkenalkan sejak dini, maka dapat berpotensi memberikan dampak buruk bagi anak-anak sebagai generasi penerus bangsa. Berdasarkan wawancara pendahuluan dengan Kepala Sekolah, selama ini peserta didik merasa bahwa obat adalah sesuatu yang pahit dan tidak enak dikonsumsi sehingga mereka enggan mematuhi aturan pengobatan. Bahkan ditemukan peserta didik yang benarbenar takut meminum obatnya saat sakit. Hasil interview pendahuluan dengan salah satu Tenaga Pengajar, diperoleh informasi bahwa pada bulan imunisasi MR tahun 2017 lalu, obat yang diberikan oleh petugas puskesmas diminumkan harus dengan sedikit paksaan agar berhasil masuk ke mulut peserta didik, bahkan didapati peserta didik yang membuang dan menolak mengkonsumsi obat.

Kurangnya pengetahuan tentang obat dan pemanfaatannya menyebabkan tujuan pengobatan tidak tercapai, selain itu dampak buruk lainnya adalah adanya potensi penyalahgunaan dan penggunasalahan obat bila kelak mereka dewasa. Rendahnya pengetahuan peserta didik mengenai profesi apoteker, obat dan pemanfaatannya menjadi masalah utama 
dalam kegiatan pengabdian kepada masyarakat ini, sehingga perlu adanya peningkatan pengetahuan, ketrampilan, yang dimotori oleh pendidikan berbasis karakter. Agar sasaran belajar dapat tercapai, maka diperlukan pendekatan-pendekatan metode pembelajaran yang sesuai dengan usia peserta didik. Penelitian yang dilakukan oleh Ahyani, L. N., (2010) [5] menyimpulkan bahwa metode Storytelling (mendongeng) sebagai stimulasi berperan dalam meningkatkan perkembangan kecerdasan moral anak usia 5 tahun yang menjadi siswa di TK B di sekolah dengan fasilitas terbatas dan bukan sekolah favorit. Anak yang mendapatkan penyampaian nilainilai moral melalui metode dongeng memiliki tingkat kecerdasan moral yang lebih tinggi dibanding anak yang tidak mendapatkan penyampaian nilai moral melalui metode dongeng. Selain itu, tingkat kecerdasan moral setelah mendapatkan nilai moral melalui metode dongeng lebih tinggi dibandingkan tingkat kecerdasan moral sebelum mendapatkan penyampaian nilai moral melalui metode dongeng.

Metode pendidikan paling efektif untuk anak usia dini adalah melalui kegiatan storytelling, sehingga anak-anak akan dapat mengembangkan imajinasinya, mengembangkan kemampuan menyimak dan mendengar secara aktif, serta dapat tersampaikan visi dan misi pendidikan karakter dengan cara menghibur dan menyenangkan. Hal senada juga dikemukakan oleh Hasanah, A., (2011) ${ }^{[6]}$, berdasarkan hasil penelitiannya diperoleh bahwa penggunaan metode cerita pada awal dan akhir pembelajaran di TK dapat meningkatkan kemampuan sosialisasi anak, kemampuan bekerjasama, simpati, empati, dukungan sosial, berperilaku akrab, komunikasi dan mengungkapkan pendapat.

$$
\text { Mengacu kepada berbagai }
$$

permasalahan di atas, kegiatan PKM ini bekerjasama dengan menggandeng Kepala Sekolah TK Senyiur Indah, yang memiliki peranan penting dalam menggerakkan tenaga pengajar lainnya melalui kegiatan belajar mengajar serta menentukan tema yang akan disampaikan kepada peserta didik dalam tematema pengajaran. Kegiatan pengabdian kepada masyarakat ini bertujuan untuk meningkatkan pengetahuan siswa didik tentang profesi apoteker dan informasi tentang obat sehingga menambah kepatuhan siswa didik dalam mengkonsumsi obat pada saat sakit, secara lebih luas mampu meningkatkan derajad kesehatan peserta didik.

\section{METODE PELAKSANAAN}

Metode pelaksanaan kegiatan pengabdian kepada masyarakat yang berlokasi di TK Senyiur Indah Semarang ini tentang pengenalan sejak dini profesi apoteker, obat dan pemanfaatannya menggunakan metode storytelling, menggunakan media peraga berupa boneka jari, serta games mengenai proses pembuatan obat dalam bentuk sediaan capsulae (kapsul). Upaya untuk menyelesaikan permasalahan yang dihadapi Mitra, diberikan solusi sesuai dengan priorotas permasalahan sebagai berikut :

1. Pengetahuan peserta didik tentang profesi apoteker masih minim, solusi yang akan dijalankan adalah peningkatan pengetahuan peserta didik tentang profesi apoteker melalui storytelling. Kegiatan mendongeng dilakukan untuk merangsang imajinasi peserta didik sekaligus menanamkan nilai-nilai moral bermuatan karakter secara menyenangkan dan menghibur. Storytelling dilaksanakan melalui alat peraga berupa boneka jari, dilakukan dengan bercerita secara langsung. Tema yang disampaikan berupa siapa itu apoteker, apa saja kewenangan dan tugasnya, serta di mana kita dapat bertemu dengan apoteker. Di akhir kegiatan storytelling, peserta didik dilibatkan dalam kegiatan diskusi dan tanyajawab untuk meningkatkan pengetahuan siswa.

2. Informasi yang diperoleh peserta didik mengenai obat dan pemanfaatannya masih terbatas, solusi yang akan 
dilakukan adalah memperluas informasi tentang obat dan pemanfaatannya melalui storytelling menggunakan alat peraga berupa boneka jari dan ditunjukkan contoh jenis-jenis sediaan obat. Materi yang diajarkan berupa bagaimana cara kita mendapatkan obat dari sarana pelayanan kesehatan yang tepat, bagaimana cara kita menggunakan obat dengan benar, bagaimana cara penyimpanan obat yang sesuai agar tidak merusak komponen obat, dan bagaimana cara membuang obat yang benar apabila sudah rusak atau kadaluwarsa. Kegiatan ini diakhiri dengan diskusi dan tanyajawab dengan peserta didik agar tercapai sasaran belajar siswa.

3. Pelayanan UKS belum maksimal, solusi dilakukan dengan memenuhi kebutuhan peralatan dan perlengkapan UKS, memberikan pelatihan petugas UKS dan tenaga pengajar dalam memberikan pelayanan UKS agar lebih maksimal.

4. Kurangnya kepatuhan siswa didik mengkonsumsi obat pada saat sakit. Permasalahan mitra dapat diatasi dengan pemberian motivasi melalui storytelling bermuatan pendidikan karakter, agar siswa menjadi paham mengenai manfaat obat bagi tubuh.

5. Perilaku peserta didik yang kurang bersahabat saat meminum obat, diatasi dengan penyuluhan dan pemberian motivasi melalui storytelling bermuatan pendidikan karakter. Selain itu dilakukan games mengenai proses pembuatan obat dalam bentuk sediaan capsulae (kapsul).

\section{HASIL DAN PEMBAHASAN}

Pelaksanaan kegiatan pengabdian kepada masyarakat ini dilakukan melalui beberapa tahapan dan menghasilkan hal-hal sebagai berikut :

1. Koordinasi dan pengurusan perizinan di TK Senyiur Indah Semarang

Koordinasi yang dilakukan dengan pihak sekolah TK Senyiur Indah Semarang ini dilaksanakan pada tanggal 9 April 2019. Dalam koordinasi ini disepakati tanggal pelaksanaan kegiatan pengabdian, sarana dan prasarana yang harus dipersiapkan, meliputi Sumber Daya Manusia (siswa TK) yang berpartisipasi aktif selama kegiatan berlangsung, tempat, sound system, LCD, serta perizinan yang disampaikan kepada pihak Sekolah.

2. Pengenalan Profesi Apoteker melalui metode storytelling

Pengenalan profesi Apoteker pada anak usia dini di TK Senyiur Indah dilaksanakan pada tanggal 31 Juli 2019. Peserta didik TK Senyiur Indah terlihat antusias mendengarkan dongeng yang menceritakan tentang seorang siswa TK tengah sakit lalu membeli obat di apotek, bukan di warung. Di apotek tersebut ia bertemu dengan Apoteker, yaitu orang yang paham tentang obat-obatan. Siswa juga dibawa ke alur cerita bahwa obat bukan "hukuman" yang harus diterima karena kenakalannya, namun obat adalah sahabat menuju sehat. Dalam dongeng tersebut ditanamkan nilai-nilai karakter religius, jujur, disiplin, mandiri, rasa ingin tahu, semangat kebahagiaan, menghargai prestasi, bersahabat/ komunikatif, peduli lingkungan, peduli sosial, serta tanggung jawab. Gambar siswa tengah mendengarkan storytelling tentang Profesi Apoteker tersaji pada Gambar 1.

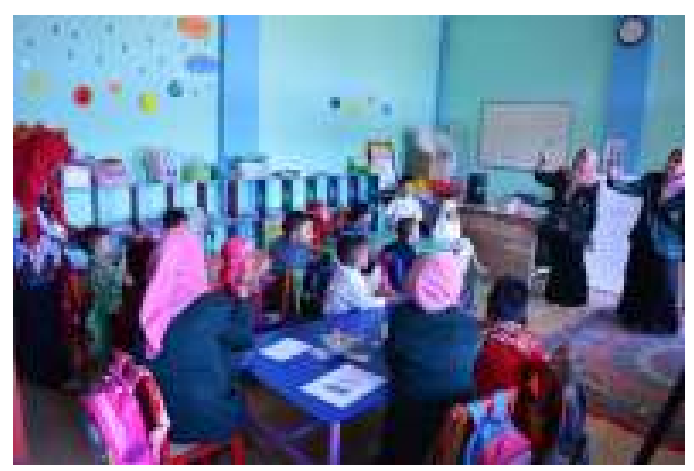




\section{Gambar 1. Pengenalan dini Profesi Apoteker melalui storytelling}

3. Games pembuatan obat dalam bentuk capsulae (kapsul)

Selain diperkenalkan dengan profesi Apoteker, peserta didik juga diberikan informasi mengenai berbagai macam bentuk sediaan obat. Kegiatan pengenalan dini profesi Apoteker dirangkai dengan games pembuatan obat dalam bentuk capsulae (kapsul) secara sederhana. Games ini bertujuan agar anak usia dini lebih mengerti tentang obat dengan cara praktek pembuatan kapsul secara langsung, sehingga mereka semakin paham dan tidak ada kekhawatiran tentang obat. Gambar games siswa membuat obat dalam bentuk kapsul tersaji pada Gambar 2. Gambar peserta didik dengan kapsul hasil buatannya tersaji pada Gambar 3.

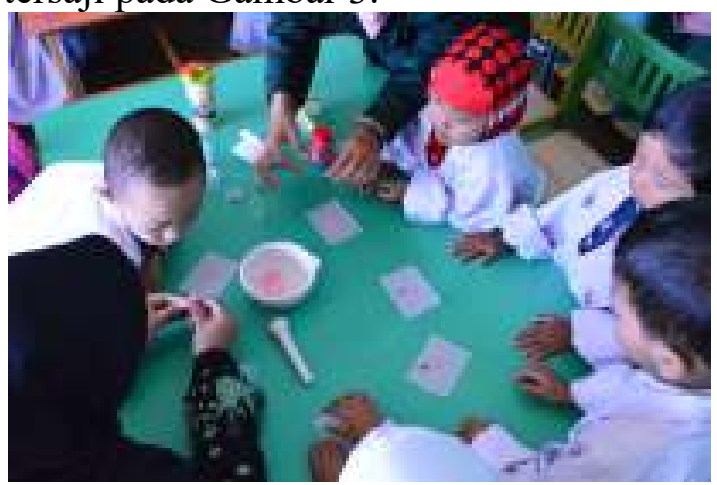

Gambar 2. Games siswa membuat obat dalam bentuk capsulae (kapsul)

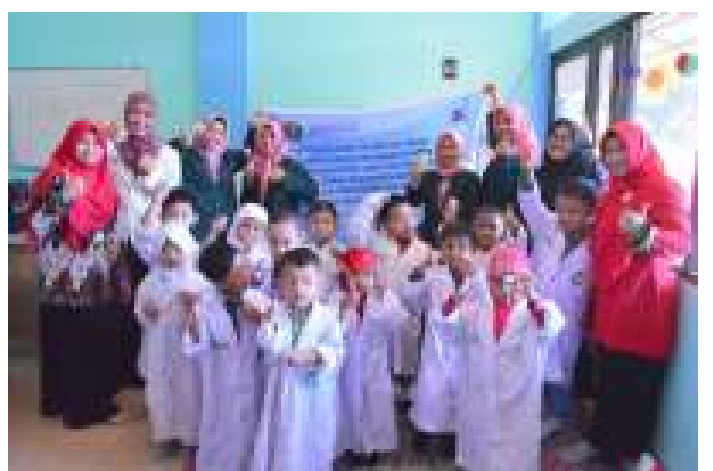

Gambar 3. Peserta didik menunjukkan hasil games pembuatan kapsul

4. Pemaparan tentang obat dan
pemanfaatannya
Dalam upaya peningkatan
$\begin{aligned} & \text { pemahaman tentang obat dan } \\ & \text { pemanfaatannya, kegiatan pengabdian }\end{aligned}$

4. Pemaparan tentang obat dan

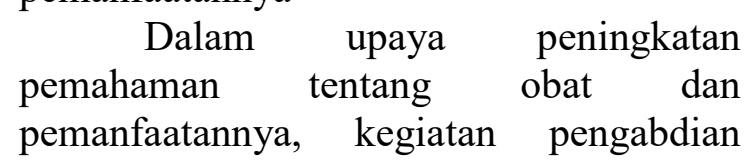

kepada masyarakat ini dilanjutkan pemberian materi DAGUSIBU (Dapatkan, Gunakan, Simpan, dan Buang) obat secara baik dan benar. Kegiatan ini dilaksanakan pada tanggal 8 Agustus 2019, yang diikuti oleh Guru serta Wali Murid. Peserta sangat antusias dengan kegiatan ini terlihat dari diskusi yang berjalan dua arah dan diskusi berjalan secara interaktif.

5. Pemenuhan kebutuhan peralatan dan perlengkapan UKS

Peralatan dan perlengkapan UKS yang tersedia di TK Senyiur Indah terlihat belum memadai, untuk itu pada kegiatan pengabdian kepada masyarakat ini dirangkai pula dengan pemenuhan kebutuhan peralatan dan perlengkapan UKS berupa timbangan badan, alat ukur tinggi badan, thermometer, antiseptic gel, minyak kayu putih, gel untuk luka memar, serta paket pertolongan pada kecelakaan.

\section{Monitoring dan evaluasi}

Proses monitoring dan evaluasi dari kegiatan pengabdian kepada masyarakat ini dipantau melalui daftar hadir peserta (minimal $80 \%$ kehadiran), dari setiap kegiatan yang dilaksanakan. Indikator tercapainya peningkatan pemahaman peserta didik tentang profesi Apoteker dapat dilihat dari peningkatan nilai dari pretest ke posttest.

\section{KESIMPULAN DAN SARAN}

Kegiatan pengabdian kepada masyarakat ini memberikan dampak positif berupa peningkatan pengetahuan dan pemahaman peserta didik TK Senyiur Indah mengenai profesi Apoteker, obat dan pemanfaatannya, sehingga menambah kepatuhan dalam menkonsumsi obat pada waktu sakit, serta secara lebih luas dapat mengoptimalkan derajad kesehatan masyarakat.

\section{UCAPAN TERIMA KASIH}

Ucapan terima kasih disampaikan kepada Direktorat Riset dan Pengabdian Masyarakat Direktorat Jenderal Riset dan Pengembangan Kementerian Riset, 
Teknologi, dan Pendidikan Tinggi yang telah mendanai kegiatan ini melalui Skema Program Kemitraan Masyarakat tahun 2019. Hal yang sama disampaikan kepada LPPM UNISSULA serta seluruh Guru dan siswa TK Senyiur Indah, Kota Semarang, Provinsi Jawa Tengah atas kerjasamanya dalam pelaksanaan kegiatan ini.

\section{DAFTAR PUSTAKA}

[1] Sidik, N., 2015, Implementasi Pendidikan Karakter dengan Dongeng pada Anak Usia Dini, Prosiding Seminar Nasional Pendidikan "Inovasi Pembelajaran untuk Pendidikan Berkemajuan", FKIP Universitas Muhammadiyah Ponorogo.

[2] Desai, C., Girdhar A.O, Shah U.H, 2005, Knowledge and Awareness about Medicines among Primary School Children in Ahmedabab, India., Regional Health Forum, Volume 9, Number 2:1-8.

[3] Arfania, M., Andayani, T. M., Rahmawati, F., 2015, Drug Related Problems Pasien Pediatrik di Instalasi Rawat Jalan Rumah Sakit, Jurnal Manajemen dan Pelayanan Farmasi, Vol 5 Nomor 2, Juni 2015.

[4] Kristina, S. A., 2014, Mengenal Lebih Dekat Peran Apoteker, Tribun Jogja, !5 Juni 2014, Halaman 15

[5] Ahyani, L. N., 2010, Metode Dongeng dalam Meningkatkan Perkembangan Kecerdasan Moral Anak Usia Prasekolah, Jurnal Psikologi Universitas Muria Kudus, Volume I No 1, Desember 2010

[6] Hasanah, A., 2011, Pelaksanaan Metode Cerita untuk Meningkatkan Kemampuan Sosialisasi Anak Usia Dini di TK Tarbiyatul Athfal 14 Plantaran Kaliwungu Kendal, Skripsi,
Fakultas Tarbiyah, Institut Agama Islam Ngeri Walisongo, Semarang.

[7] Afandi, M., Chamalah, E., Wardani, O. P., 2013, Model dan Metode Pembelajaran di Sekolah, Cetakan Pertama, Unissula Press. 